\title{
Preventing inbreeding depression in Anacamptis coriophora (Orchidaceae) as a model of food-rewarding orchid
}

\author{
Miquel Capó $\mathbb{B} \cdot$ Sebastià Perelló-Suau $\mathbb{B} \cdot$ Juan Rita $\mathbb{C}$
}

Received: 25 December 2020/ Accepted: 4 January 2022 / Published online: 21 January 2022

(C) The Author(s) 2022

\begin{abstract}
Pollination of deceptive orchids has enabled scientists to understand how these species avoid inbreeding depression by reducing the number of pollinator visits per inflorescence. In rewarding species, which receive a higher rate of visits per plant, geitonogamy is usually higher and therefore the risk of inbreeding increases. In this study, we assess the breeding system of the rewarding orchid A. coriophora, and the spatio-temporal changes in its fitness as well as variation in nectar content after pollination. We found that the species partially selects allogamous pollen if pollinia from the same stalk and other plants arrive to the stigma. Furthermore, when self-pollination occurs, despite successful fructification, seed viability is significantly lower than that of crosspollinated plants. A. coriophora exhibits spatio-temporal variation in fitness that does not correlate with any plant feature. Moreover, nectar volume is reduced after pollination, but the sugar concentration is maintained. This study emphasizes how essential the pre-zygotic and post-zygotic reproductive barriers are for rewarding orchids to avoid inbreeding depression.
\end{abstract}

Communicated by Timothy Bell.

M. Capó $(\bowtie) \cdot$ S. Perelló-Suau · J. Rita

Laboratory of Botany, Research Group on Plant Biology under Mediterranean Conditions, Department of Biology, University of the Balearic Islands, Palma, Spain

e-mail: miquel.capo@uib.es
Keywords Orchidaceae - Pollination system · Inbreeding depression · Geitonogamy · Pollination ecology

\section{Introduction}

The strategies used by orchids to attract pollinators are a key factor in their fitness, and the selective forces that have driven their evolution are a key topic in evolutionary biology. The species of the Orchidaceae family are predominantly self-compatible (Gontijo et al. 2010), but spontaneous self-mating is rare, and it has been documented in only a few number of species (Darwin 1887; Peter and Johnson 2009). In most cases, fecundation is pollinator-mediated (Neiland and Wilcock 1995). The mechanisms by which orchids attract pollinators have been studied for a long time due to the extraordinary evolutionary success of deception. Almost one-third of all orchids are reported to be deceptive (Tremblay et al. 2005; Renner 2006), with food deception [e.g. a wide range of species of Orchis and Anacamptis genera; (Jersáková et al. 2009; Wong et al. 2017)], sexual deception [e.g. Ophrys species (Schiestl et al. 2000)] or oviposition deception [e.g. Gastrodia species (Martos et al. 2015)] the most common strategies. How deceptive strategies evolved in the light of natural selection has been an intriguing topic since Darwin (Darwin 1887). 
Deception usually implies a limited number of pollinator species (Tremblay 1992) and in some cases, species-specific pollinators (Aguado Martín et al. 2016). In the case of food deception, floral traits such as showy colours in the corolla, nectar indicator marks, or the presence of spurs induce pollinators to visit the flowers (Jersáková et al. 2006). Nevertheless, the evolutionary advantage of obligate deception is intriguing, as these plants have a lower reproductive output than rewarding plants (Neiland and Wilcock 1998; Schiestl 2005; Jacquemyn et al. 2009) due to the scarcity of pollinator visits (Tremblay et al. 2005). The most commonly accepted hypothesis to explain the selective advantage of rewardless strategies is that they favour cross-fertilization and reduce the risk of inbreeding depression (Johnson and Nilsson 1999; Johnson et al. 2004; Jersáková et al. 2006; Suetsugu et al. 2015) especially in European orchids, for which self-incompatibility has not been reported (Neiland and Wilcock 1995). Pollinators are generally visiting one or a few flowers per inflorescence in deceptive species as they do not get any reward (Jersáková et al. 2006). This behaviour reduces the risk of geitonogamy and enhances pollen transport among plants, which may explain the evolutionary success of deception (Jersáková and Johnson 2006) but see Kropf and Renner (2008).

Less attention has been paid to the pollination of rewarding orchid species (Smithson 2002; Johnson et al. 2003; Internicola et al. 2006; Duffy and Stout 2011). Despite being less pollinator-limited (Jersáková et al. 2006), but see Brys et al. (2008), rewarding species are at high risk of selfing as pollinators usually visit several flowers of the same inflorescence, thus, the risk of inbreeding depression is considerable (Jersáková et al. 2008). In self-compatible species, seed quality and seed production are reported to reduce after autogamous pollination events (Tremblay et al. 2005; Jersáková et al. 2008). In this sense, both fruit set and seed quality must be considered in reproductive output studies. Many researchers have aimed to assess whether the presence of nectar is positively or negatively correlated with fitness of orchid species and populations. For instance, Jersáková et al. (2008) stated that the absence of nectar in many orchid species was detrimental to pollination success, but that lower fruit set values with good quality seed production could be an optimal evolutionary strategy for orchids. Similarly, Johnson and
Nilsson (1999) observed an increase in pollen deposition once Anacamptis morio and Orchis mascula were nectar supplemented, but Smithson and Gigord (2001) showed the opposite trend in Himantoglossum robertianum. Interestingly, experiments assessing how non-used nectar is reallocated in plant tissues showed that sugars were reinvested in structures of the pericarp in Platanthera chlorantha (Nepi and Stpiczyńska 2007) and in ovules formation in Epipactis palustris (Bednara et al. 1981), which implies not only an energy-saving strategy but also an optimization of fruit and embryo development.

Fruit set and seed set have been widely used as fitness indicators for orchids, while few studies have focussed on male function such as pollinia removal rate, which is an easy-to-measure proxy for male fitness (Anders Nilsson 1992; Parra-Tabla et al. 2000; Capó et al. 2020b). These data are crucial to assess the pollen transfer efficiency (PTE) and improper pollen transfer (IPT) (Parra-Tabla et al. 2000; Tremblay and Ackerman 2007; Duffy and Stout 2011), both of which are related to pollination deficit or fidelity of the pollinators to the target species. For instance, sexually-deceptive species experience less pollen loss than food-deceptive species because of their strong specific-pollinator dependence (Scopece et al. 2015). On other hand, we could hypothesize that male and female fitness could vary between orchids that offer a reward and orchids that deceive pollinators. Nevertheless, both fruit set and seed viability could be affected by the ecological context, such as climatic conditions (Price et al. 2005), differential grazing impacts (Cursach et al. 2013; Capó et al. 2020b) and the density and composition of neighbouring co-flowering plants (Jacquemyn and Brys 2010; Tremblay et al. 2010; Duffy and Stout 2011; Borràs and Cursach 2020). Moreover, plant morphology and population structure are also likely to be important. Parameters such as plant height, inflorescence size, flower number, spur length, population size, flowering time and canopy density have been demonstrated to affect or influence fitness (Scopece et al. 2017; Capó et al. 2020a). Thus, monitoring of the within-species variation in individual fitness is important to obtain a more realistic overview of the reproductive biology of these species.

Mediterranean orchids are tuberous, herbaceous plants with a winter-spring cycle and summer dormancy (Blondel et al. 2010). The Balearic Islands 
archipelago, located in the western Mediterranean basin, is home to approximately 40 Mediterranean orchid species (Alomar et al. 1994); the reproductive ecology and plant-pollinator interactions of these species have received little investigation. We studied Anacamptis coriophora, one of the few nectar-rewarding orchid species native to the Balearic Islands, to better understand the evolutionary advantage of offering nectar as a reward to pollinators compared to other deceptive species that live in the same habitats. The specific aims of our work were (i) to evaluate the breeding system of the A. coriophora species and the interaction between autogamous and cross pollen on the stigma; (ii) to analyse the spatio-temporal variations in both male and female fitness and identify the relationships with biometric parameters (plant height, inflorescence length and flower number) in three different populations over three years and (iii) to estimate the changes in both nectar quantity (volume) and quality ( ${ }^{\circ}$ Brix) before and after pollination. The hypotheses of this work are that (i) cross-pollination would be favoured against self-pollination, even if both outcross and self-pollen coexist in the stigma, (ii) as a consequence of rewarding, inbreeding or late selfincompatibility would appear in self-pollination events, (iii) fitness would vary among years and sites depending on their ecological factors, and biometric parameters might influence to the pollinator visitation rate and (iv) nectar volume and concentration would be reduced after visitation to reinvest energy in other plant tissues as observed in other orchid species.

\section{Materials and methods}

Study system

Anacamptis coriophora (L.) R.M.Bateman, Pridgeon and M.W.Chase (= A. fragrans RM Bateman) is a Mediterranean orchid species distributed throughout the Mediterranean basin from the Balkans to Israel (Vázquez Pardo 2009). The species is considered endangered in some regions, including France (Rankou 2011). The flowering stalks of A. coriophora are ca. 14-37 (60) cm in height and can have 6-29 (100) flowers. In the Balearic Islands, the first leaves sprout in October; the flowering period begins between March and April; and the leaf rosettes wither in early June (pers. obs.). The habitat is very variable, from
Mediterranean shrublands on calcareous hillsides to sand dunes (Smithson 2006). The co-flowering plants in those habitats are diverse in both abundance and floral traits.

This study was performed on the island of Mallorca (Balearic Islands) where the species is widespread. The populations studied were Son Bosc $\left(39^{\circ} 46^{\prime} \mathrm{N}, 3^{\circ}\right.$ $07^{\prime} \mathrm{E}$ ), El Toro (39 $28^{\prime} \mathrm{N}, 2^{\circ} 29^{\prime} \mathrm{E}$ ) and Xorrigo (39 $34^{\prime} \mathrm{N}, 2^{\circ} 48^{\prime} \mathrm{E}$ ). A bagging experiment was carried out to assess the breeding system in the Son Bosc population, which consists of a diverse dune marshland with a high number of individuals and many coflowering species (mainly Teucrium dunense Sennen, Helichrysum stoechas (L.) Moench, Lotus cytisoides L., Blackstonia perfoliata (L.) Huds. and Gladiolus communis L.). Spontaneous pollination events were assessed during 2016 and hand-pollination treatments during 2018. The change in nectar content after pollination was also analysed in the same population during 2018.

Moreover, spatio-temporal variations in biometric and reproductive parameters were assessed in Son Bosc, El Toro and Xorrigo during 2015, 2016, 2017 and 2018 ( $n=30$ individuals per population per year).

\section{Breeding system}

The breeding system of A. coriophora was studied following the methodology of Suetsugu et al. (2015) and Smithson (2006). Bags with a mesh net of $1.20 \mathrm{~mm}$ were used for pollinator exclusion experiments in Son Bosc in 2016 and 2018. In 2016, agamospermy $(n=40)$ was assessed by emasculating flowers and bagging them to avoid pollination (fruit formation by asexual mechanisms); and spontaneous self-pollination $(n=40)$ to determine the capacity of the plant to self-reproduce with no pollinator activity. During 2018, the study focussed on hand-pollination treatments (by fecundation of treated flowers using a single pair of pollinia in each treated flower), which consisted of self-pollination ( $n=42$ flowers from 23 individuals), to test the self-compatibility of the plant by hand-pollinating stigmas with pollen from the same flower; cross-pollination $(n=49$ flowers from 29 individuals), to estimate cross-compatibility among individuals of the same population by pollinating stigmas with pollen from other plants within the same population; and inter-population cross-pollination ( $n=46$ flowers from 16 individuals), to assess if 
pollen from other populations had a different reproductive efficiency to that of plants from the same population, assessed by pollinating stigmas with pollen from plants of populations $>10 \mathrm{~km}$ away. Furthermore, to disentangle the capacity of gynoecium to favour outcross over self-pollen, additional treatments with both self and cross pollen were performed. First, pollen from the same flower was used for handpollination. After $4 \mathrm{~h}$, the same flower was pollinated by pollinia from another individual from the same population (self + cross-pollination, $n=48$ flowers from 25 individuals). The effect of pollen competition when allogamous pollination occurred first was also studied (cross + self-pollination, $n=41$ flowers from 21 individuals). Wind transport mechanisms were not considered as wind-mediated pollen transport does not occur in the Orchidaceae family (Jersáková et al. 2006). The experimental design consisted on bagging the whole inflorescences and mixing different treated flowers within the same inflorescence to avoid random effects. Non-treated plants were used as control individuals, coinciding with those used in the spatiotemporal analysis (see below). The variables examined in this study were fruit set (defined as the number of capsules formed in each treatment per total number of flowers tested) and the percentage of viable seeds (defined as the number of seeds with embryos per total number of seeds counted) based on between 600 and 1100 seeds (or the entire seed content, if lower) sampled randomly from each fruit (see the limitations of seed set values for orchid reproductive studies in Suetsugu et al. (2015).

Statistical analysis was performed in $\mathrm{R}$ version 3.3.2 ( $\mathrm{R}$ Core Team 2019) via a generalized linear model (GLM) using a binomial error structure and logit link for all models, using fruit set and seed viability as response variables. To assess the capacity to reproduce without pollinators, pollination treatments were used as predictor (using control, agamospermy and spontaneous self-pollination as levels). Distance of pollen origin was studied using pollination treatments as predictor (using control, cross-pollination (within the same population) and inter-population cross-pollination as levels). Also, to evaluate the selection of pollen in the stigma; control, self-pollination, self + cross-pollination, cross + self-pollination and cross-pollination were used as levels of the pollination treatment predictor. To evaluate significant differences, we used 'Anova' function (Type II) from the 'car' package (Fox and Weisberg 2019). Ad hoc analysis was performed using 'lsmeans' function from the 'lsmeans' package based on the Tukey t-test calculation. Estimations of the inbreeding depression index $(\delta)$ and cumulative inbreeding depression index $\left(\delta_{\mathrm{c}}\right)$ were obtained using the formulae of Charlesworth and Charlesworth (1987) and Capó et al. (2020b), respectively, as follows:

$$
\begin{array}{r}
\delta=1-\text { (self-pollination fitness traits/ } \\
\text { cross-pollination fitness traits) }
\end{array}
$$

$$
\begin{aligned}
\delta_{\mathrm{c}}=1 & -((\text { self-pollination fruit set } / \\
& \text { cross-pollination fruit set }) \\
& \times(\text { self-pollination percentage of viable seeds } / \\
& \text { cross-pollination percentage of viable seeds }))
\end{aligned}
$$

Moreover, we calculated the pollen limitation index (PL) using the Larson and Barrett (2000) equation, as follows:

$$
\begin{aligned}
\mathrm{PL}= & 1 \\
& -(\text { control fruit set } / \text { cross-pollination fruit set }) .
\end{aligned}
$$

Spatio-temporal variation in natural populations

We measured 30 individuals from three populations during 3 years ( $n=90$ individuals each year) considering three biometric parameters related to visibility of the plant: (i) plant height (h), measured from the basal part of the flowering stalk to the apex of the youngest flower in the inflorescence; (ii) inflorescence length (1), measured from the most basal flower to the apex; and (iii) the number of flowers per inflorescence. Plants were measured when the fruits were welldeveloped, during seed development. The fruit and seed set value was obtained by recording the number of fruits formed in each inflorescence and the percentage of viable seeds in 30 fruits from randomly selected individuals.

Withered corollas were collected in each population during senescence of the inflorescences, when the fruits were completely formed. The samples were observed at $10 \times$ under a stereomicroscope to determine the presence/absence of pollinia. If only one pollinia was present, the event was considered a pollinator visit but with only one pollinium exported. Thus, the pollinia removal rate was calculated as the 
number of pollinia exported per total number of pollinia of the individual.

Statistical analysis was conducted using a GLM with a binomial error structure and logit link for fruit set, seed viability percentage and pollinia removal rate; a linear model (LM) with a normal error structure for height and inflorescence length; and a GLM with a Poisson error structure and log link for the number of flowers. The explanatory variables were localities $(n=3)$, years $(n=3)$ and the interaction between localities and years, and the response variables were height, inflorescence length, number of flowers, fruit set percentage and pollinia removal rate. As mentioned above, significant differences among explanatory variables were analysed by 'Anova" function (Type II) from the 'car' package (Fox and Weisberg 2019) and Ad hoc analysis was executed using 'Ismeans' function from the 'Ismeans' package based on the Tukey t-test calculation. Moreover, to examine the correlations between both biometrical and ecological parameters (height, inflorescence length, flower number, fruit set and pollinia removal rate), a correlation matrix was generated using 'ggpairs' function from the 'GGally' package considering Spearman rank coefficients.

Evaluation of nectar content after pollination

To assess the capacity of the species to reabsorb remnant nectar from the spur after pollination, a quantitative (volume) and qualitative ( ${ }^{\circ}$ Brix) analysis of the nectar content was performed. Prior to the flowering season, 20 flowers of the same age were bagged to prevent visits. Ten flowers were handpollinated with pollen from another individual (simulating cross-pollination) and 10 unpollinated flowers were used as a non-visited group. Plants were bagged after treatments. After 4 days, the flowers were collected and nectar from the spurs was quantified using micro-pipettes (Drummond Microcaps ${ }^{\circledR}$ ) and ${ }^{\circ}$ Brix values were obtained using a refractometer $\left(\right.$ Eclipse, Bellingham + Stanley $\left.{ }^{\mathrm{TM}}\right)$. Statistical analysis was conducted using a linear model considering nectar volume and nectar concentration as response variables and pollination treatment (open pollination and hand pollination) as a predictor. Significant differences and Ad hoc analysis were assessed as explained in previous sections.

\section{Results}

Pollination system of A. coriophora

Bagging treatments are summarized in Fig. 1. Nonassisted pollination treatments failed to set fruits by both agamospermy and spontaneous selfing compared to open-pollinated control individuals $(\mathrm{df}=2$, $\left.\chi^{2}=350.93, p<0.001\right)$. On the other side, distance of the pollen origin showed higher fruit set in control than in assisted treatments $\left(\mathrm{df}=2, \chi^{2}=350.93\right.$, $p<0.001)$ but no differences were detected between intra-population and inter-population cross-pollination $(t=-0.49, p=0.626)$ neither among treatments for seed viability $\left(\mathrm{df}=2, \quad \chi^{2}=494.29\right.$, $p<0.001)$. Fruit set was similar between both pollen selection treatments (Self + Cross and Cross + Self) and lower than control plants $\left(\mathrm{df}=4, \chi^{2}=118.24\right.$, $p<0.001$ ). Interestingly, seed viability was lower in the self-pollination treatment than in other treatments (df $\left.=4, \chi^{2}=9627.2, p<0.001\right)$.

The inbreeding depression index $(\delta)$ values were 0.15 for fruit set, but 0.77 for seed viability percentage. The resulting cumulative depression index obtained from these values was 0.88 . The pollen limitation index was -0.53 , indicating that the amount of pollinia arrived to flowers was higher in open-pollinated plants than in the treatments.

Spatio-temporal variations in plant traits and reproductive success

The dry spring season with remarkable climatological anomalies that occurred in 2016 (Ramis et al. 2017) affected the flowering development of A. coriophora, as observed for other orchid species in the same year (Capó et al. 2020b). Localities with smaller populations as Xorrigo and El Toro did not flower in that year. However, the population of Son Bosc showed a good flowering event that year, possibly due to the increased availability of water and wetter soils in this locality, which is close to the s'Albufera de Mallorca wetland.

Plant traits were analysed using different models (GLM or LM) and adjusting data depending on the type of variables (normal, poisson or binomial types). All statistical results are summarized in Table 1. The drought observed in 2016 did not allow the El Toro and Xorrigo populations to flower successfully. 


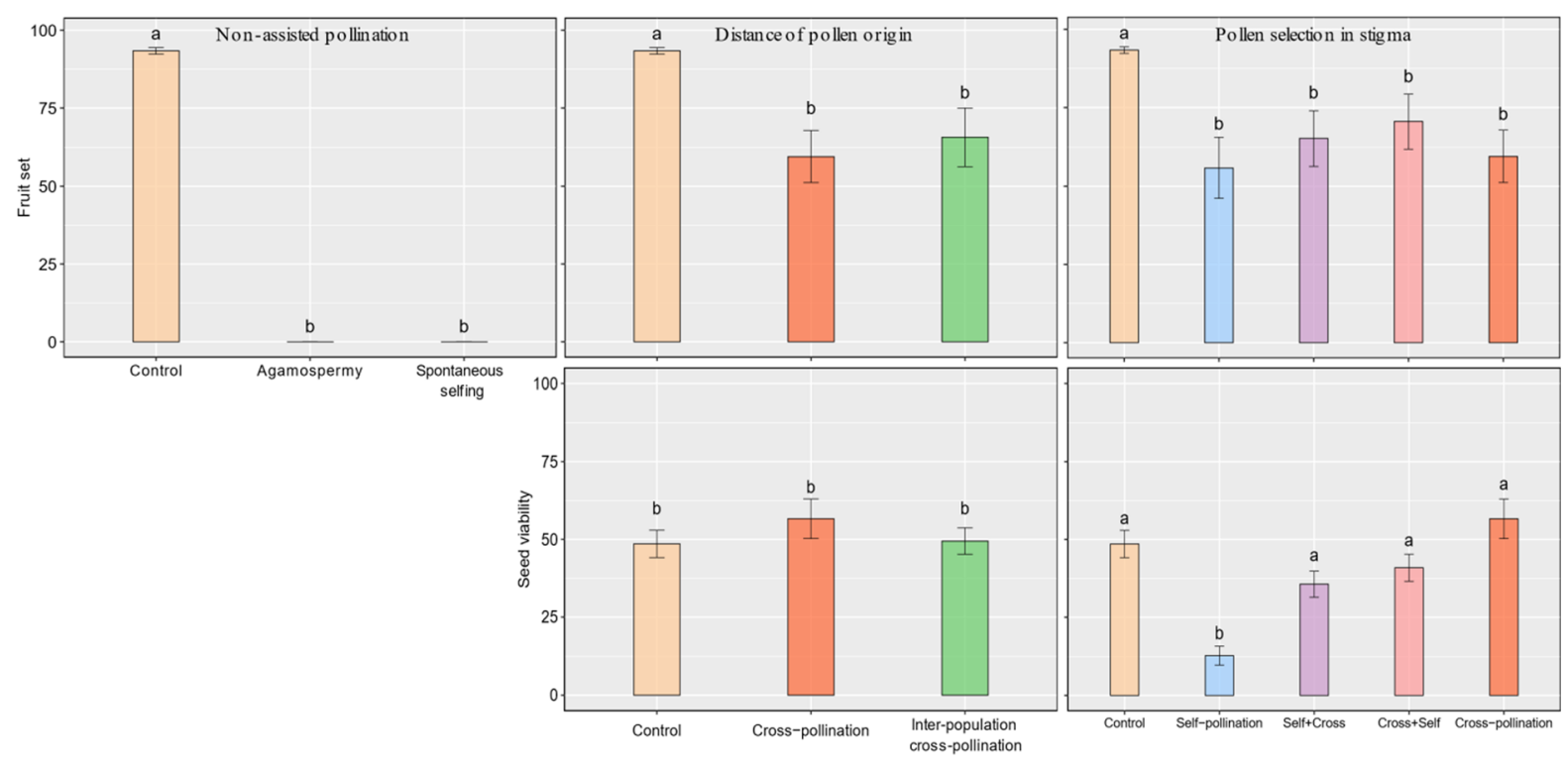

Fig. 1 Mean fruit set (above) and seed viability (below) in the bagging experiment. Error bars indicate standard error. Letters indicate Tukey post hoc groups

However, plant traits were assessed that year in Son Bosc population and showed high values for fruit set $(88.85 \pm 1.04)$, pollinia removal rate $(85.10 \pm 1.50)$ and seed viability percentage $(54.55 \pm 2.90)$. Height and inflorescence length were significantly different between the populations in 2017 (height, $\mathrm{df}=2$, $F=33.06, p<0.001$; inflorescence length, $\mathrm{df}=2$, $F=21.26, p<0.001$ ) and 2018 (height, $\mathrm{df}=2$, $F=36.47, p<0.001$; inflorescence length, $\mathrm{df}=2$, $F=25.12, p<0.001$ ), but not between years comparing all populations (height, $\mathrm{df}=2, F=0.64$, $p=0.526$; inflorescence length, df $=2, F=2.428$, $p=0.109$ ). The tallest plants with larger inflorescences were reported in Son Bosc every year (in 2018; $h=26.01 \mathrm{~cm} \pm 0.79$ and $l=8.63 \mathrm{~cm} \pm 0.43)$; the plants at this site also had the maximum average flower number (28). On other hand, El Toro and Xorrigo showed similar values for all plant traits studied (in 2018; $h=16.16 \mathrm{~cm}( \pm 0.86), 18.53 \mathrm{~cm}$ $( \pm 1.26)$ and $l=5.14( \pm 0.25) \mathrm{cm}, 6.23 \mathrm{~cm}( \pm 0.38)$, respectively).

Plant fitness traits (fruit set, pollinia removal rate and seed viability percentage) exhibited spatio-temporal variation (Fig. 2). Fruit set showed the most remarkable differences between years in El Toro ( $\left.\mathrm{df}=1, \chi^{2}=42.32, p<0.001\right)$ where it varied from $21.84 \%$ ( \pm 3.85$)$ in 2017 to $88.93 \%( \pm 2.23)$ in 2018 . Pollinia removal rate increased among years $(\mathrm{df}=1$, $\chi^{2}=42.32, p<0.001$ ), especially in Xorrigo and El Toro. Seed viability percentage was similar among populations ( $\mathrm{df}=2, F=1.97, p=0.141$ ), though significant differences were observed between years (df $=2, F=11.96, p<0.001)$ increasing in El Toro and Xorrigo and maintaining in Son Bosc.

The correlation matrix for the monitored parameters (Fig. 3) revealed significant correlations between height and flower number $(\rho=0.70)$, height and inflorescence size $(\rho=0.80)$, and flower number and inflorescence size $(\rho=0.81)$, but reproductive traits (fruit set, pollinia removal rate and seed viability percentage) did not show any significant correlations with biometric plant traits.

Nectar content after pollination

Four days after the pollination of non-visited flowers was sufficient time to observe that corolla senescence was faster in hand-pollinated flowers compared to receptive flowers (pers. obsv.). As shown in Fig. 4, hand-pollinated flowers had a significantly lower nectar volume $(\max =0.6 \mu \mathrm{L})$ than non-pollinated flowers $\quad(\min =0.7 \quad \mu \mathrm{L} ; \quad \mathrm{df}=1, \quad F=12.39$, $p$ value $=0.002)$. In fact, of the 10 hand-pollinated plants used in the experiment, only three of them presented nectar in the spur $(0.38,0.59$ and $0.60 \mu \mathrm{L})$ four days after hand-pollination. Thus, the nectar 
Table 1 Analysis of the variance or deviance of fitness traits (fruit set, percentage viable seeds and pollinia removal rate) and biometric traits (height, inflorescence length and flower number). Significance levels are indicated in bold and with asterisks

\begin{tabular}{|c|c|c|c|c|}
\hline & df & $X^{2}$ & $F$ & $\begin{array}{l}P(F) / P \\
\left(X_{2}\right)\end{array}$ \\
\hline \multicolumn{5}{|c|}{ Height (cm) - LM Normal } \\
\hline Year & 1 & & 2.17 & 0.14 \\
\hline Location & 2 & & 77.76 & $<0.001 * * *$ \\
\hline Year:Location & 2 & & 0.64 & 0.52 \\
\hline Residuals & 186 & & & \\
\hline \multicolumn{5}{|c|}{ Inflorescence length (cm) - LM Normal } \\
\hline Year & 1 & & 0.92 & 0.33 \\
\hline Location & 2 & & 60.35 & $<0.001 * * *$ \\
\hline Year: location & 2 & & 2.42 & 0.09 \\
\hline Residuals & 186 & & & \\
\hline \multicolumn{5}{|c|}{ Flower number - GLM Poisson } \\
\hline Year & 1 & 3.98 & & $0.04 *$ \\
\hline Location & 2 & 263.82 & & $<0.001 * * *$ \\
\hline Year: location & 2 & 0.74 & & 0.68 \\
\hline Residuals & 186 & 356.21 & & \\
\hline \multicolumn{5}{|c|}{ Fruit set (\%) - GLM Binomial } \\
\hline Year & 2 & 402.68 & & $<0.001 * * *$ \\
\hline Location & 2 & 391.21 & & $<0.001 * * *$ \\
\hline Year: location & 2 & 92.14 & & $<0.001 * * *$ \\
\hline Residuals & 188 & & & \\
\hline \multicolumn{5}{|c|}{ Seed viability (\%) - GLM Quasibinomial } \\
\hline Year & 2 & 135.49 & & $<0.001 * * *$ \\
\hline Location & 2 & 245.98 & & $<0.001 * * *$ \\
\hline Year: location & 2 & 188.30 & & $<0.001 * * *$ \\
\hline Residuals & 154 & & & \\
\hline \multicolumn{5}{|c|}{ Pollinia removal rate $(\%)$ - GLM Quasibinomial } \\
\hline Year & 1 & 783.26 & & $<0.001 * * *$ \\
\hline Location & 2 & 340.95 & & $<0.001 * * *$ \\
\hline Year: location & 2 & 2776.46 & & $<0.001 * * * *$ \\
\hline Residuals & 197 & & & \\
\hline
\end{tabular}

concentration could only be assessed in those samples, which limited the sample size to $n=3$. Despite this, the sugar content of hand-pollinated plants (30.00 ${ }^{\circ}$ Brix \pm 5.75 ) was not significantly different $(t=0.11, \mathrm{df}=3.43, p$ value $=0.916)$ to that of receptive plants $\left(29.25^{\circ} \mathrm{Brix} \pm 3.28\right)$.

\section{Discussion}

Reproductive success in a rewarding orchid

As it occurs in many orchids worldwide, particularly European orchids (Neiland and Wilcock 1995), in A. coriophora agamospermy and spontaneous selfing failed, indicating this species depends on pollinators to produce seeds. Furthermore, as observed for both rewarding and rewardless orchids-and also A. coriophora as reported by Smithson (2006) and Dafni and Ivri (1979) — the fruit set was similar in both self- and cross-pollination treatments. Nevertheless, in our target species seed viability differed significantly between self- and cross-pollination, with a significant reduction in seed viability after self-pollination. The inbreeding depression index value for fruit set is low (0.15), but early abortion of embryos observed in fruits from selfing treatments notably increased the inbreeding depression index in this stage (0.77). Thus, the cumulative inbreeding depression index $\left(\delta_{\mathrm{c}}\right)$ for both stages was 0.88 , one of the highest inbreeding depression index values reported for orchids (Smithson 2006), and similar to other rewarding species such as Gymnadenia conopsea (Sletvold et al. 2012) but much higher than in non-rewarding species. In this sense, our results indicate that inbreeding depression tends to be high in rewarding species according to Charlesworth and Charlesworth (1987). Despite that, Smithson (2006) did not find any differences in fitness traits between rewarding and non-rewarding orchids. In this scenario, A. coriophora is close to be functionally self-sterile (only produce $18 \%$ of potential seeds in self treatments) unlike rewardless orchids such as Anacamptis longicornu (Capó et al. 2020b) or A. morio (Smithson 2006). It is not easy to assess whether this massive failure in embryo development is caused by inbreeding depression at this stage, which is related to abortion due to high amount of deleterious alleles (Sletvold et al. 2012) or by late-acting selfincompatibility (LSI), which occurs when pollen tubes are inhibited in the ovary before reaching the ovules (Seavey and Bawa 1986; Borba et al. 2001). More studies will be needed to identify the precise genetic mechanism driving this process. 


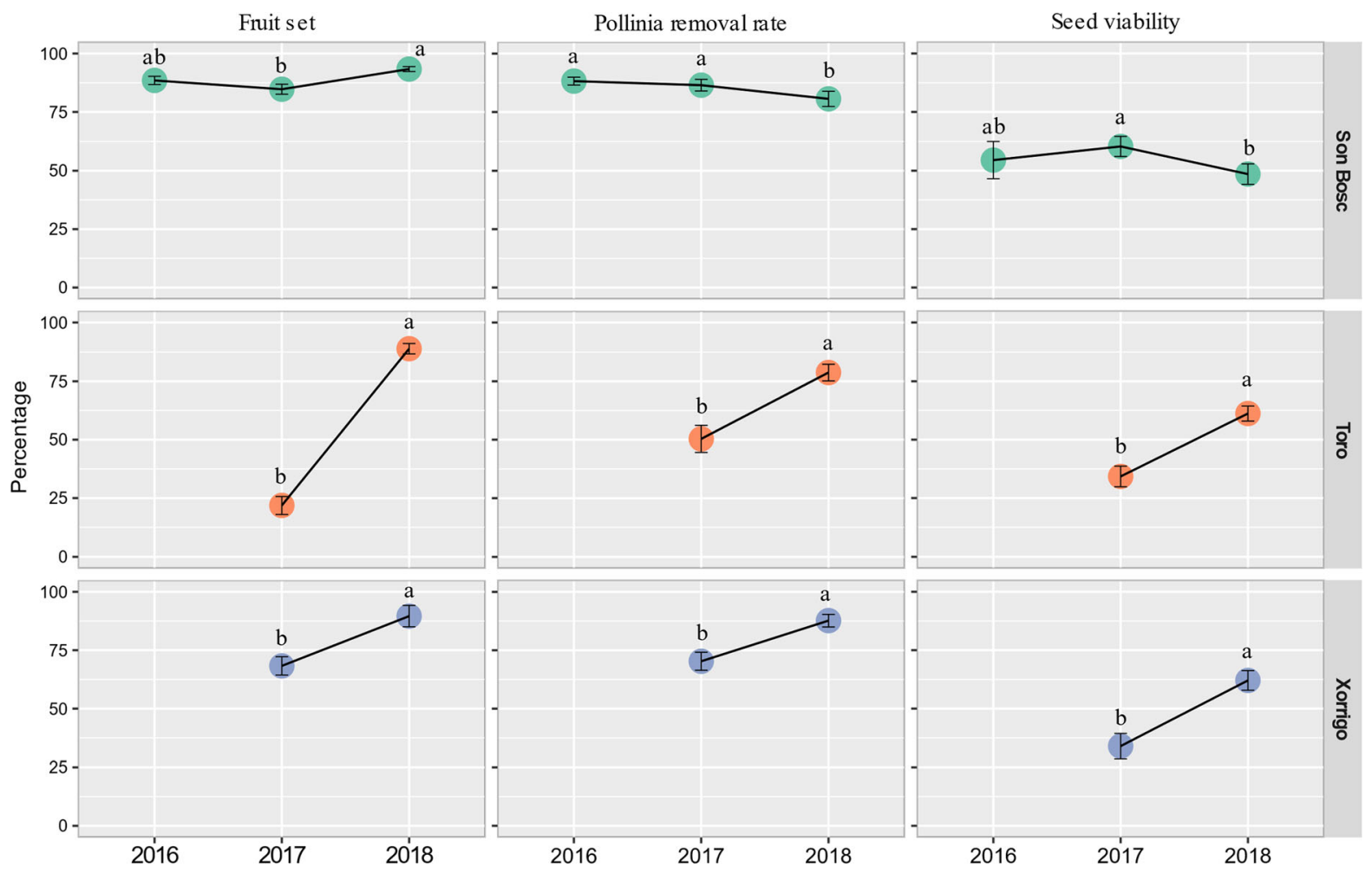

Fig. 2 Mean control fruit set, pollinia removal rate and seed viability for each population studied during three consecutive years. Error bars indicate standard error. Letters indicate Tukey post hoc groups

The mechanism of LSI reduces the risk of inbreeding depression via autogamy (either by intra-flower self-pollination or geitonogamy) and promotes genetic variability to next generations by reducing the proportion of seeds that originate from selfing. As explained above, this strategy differs to the processes observed in many rewardless species (Harder and Barrett 1995; Mitchell et al. 2004). Thus, rewarding A. coriophora may have developed a mechanism concordant with the hypothesis of inbreeding depression avoidance as a driving evolutionary force (Jersáková and Johnson 2006) taking into account that inbreeding depression manifests itself in others stages of the plant life besides seed formation. On the contrary, deception in rewardless species would have promoted premating avoidance of inbreeding and LSI would not necessarily originate. Moreover, no significant differences in fruit set and seed viability percentage were observed between the combined pollen treatments (Cross + Self and Self + Cross) for A. coriophora These results might indicate that in the scenario where a stigma receives pollen from both self and cross origins, the allogamous pollen is preferably selected. Pollen competition may help the plant to reduce the risk of inbreeding, as reported by Armbruster and Rogers (2004). This process acts as another barrier to reduce the risk of selfing, as observed for seed viability (see above). Indeed, our results indicate that seed viability was similar between control flowers and the cross-pollination treatments, and significantly higher than that of the self-pollination treatment. If geitonogamy was a common process in nature, we would expect lower seed viability in control fruits than those from cross treatments.

On the other hand, the pollen limitation index had a negative value, which may indicate that flowers require the arrival of very large amounts of pollen to be properly pollinated and that in the studied population flowers presented no limitation in pollen arrival to be properly pollinated. Indeed, we have observed how a lot of pollinators visit many flowers of this species and collect a large amount of pollinia on their heads, in contrast to deceptive species (Fig. 5) in which it is very difficult to observe pollinator visits. 

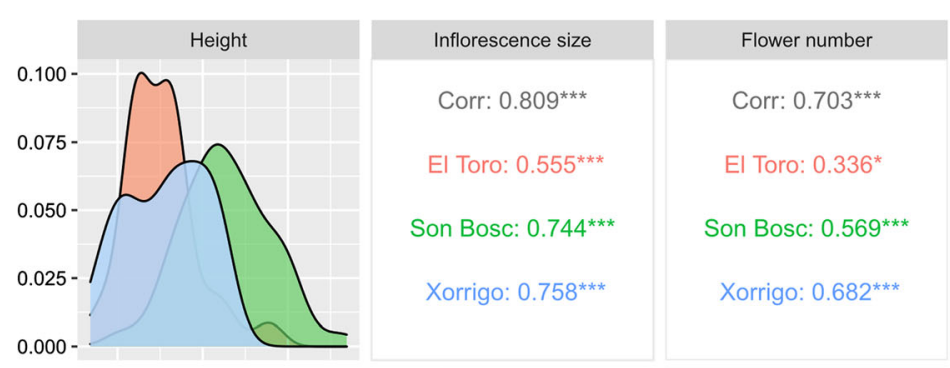

Pollinia removal rate
Corr: $0.313^{* * *}$

Fruit Set
Corr: $0.359^{* * *}$
El Toro: $0.286^{*}$
Son Bosc: -0.139
Xorrigo: $0.482^{* *}$
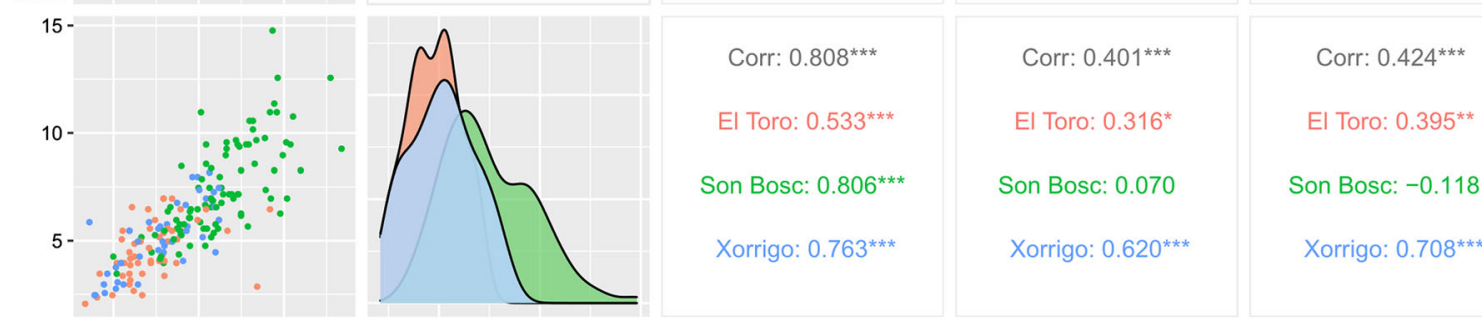

\section{Son Bosc: $0.806^{\star * *}$}

Son Bosc: 0.070

Son Bosc: -0.118

Xorrigo: $0.763^{\text {*** }}$

Xorrigo: $0.620^{* \star *}$

Xorrigo: $0.708^{* * *}$
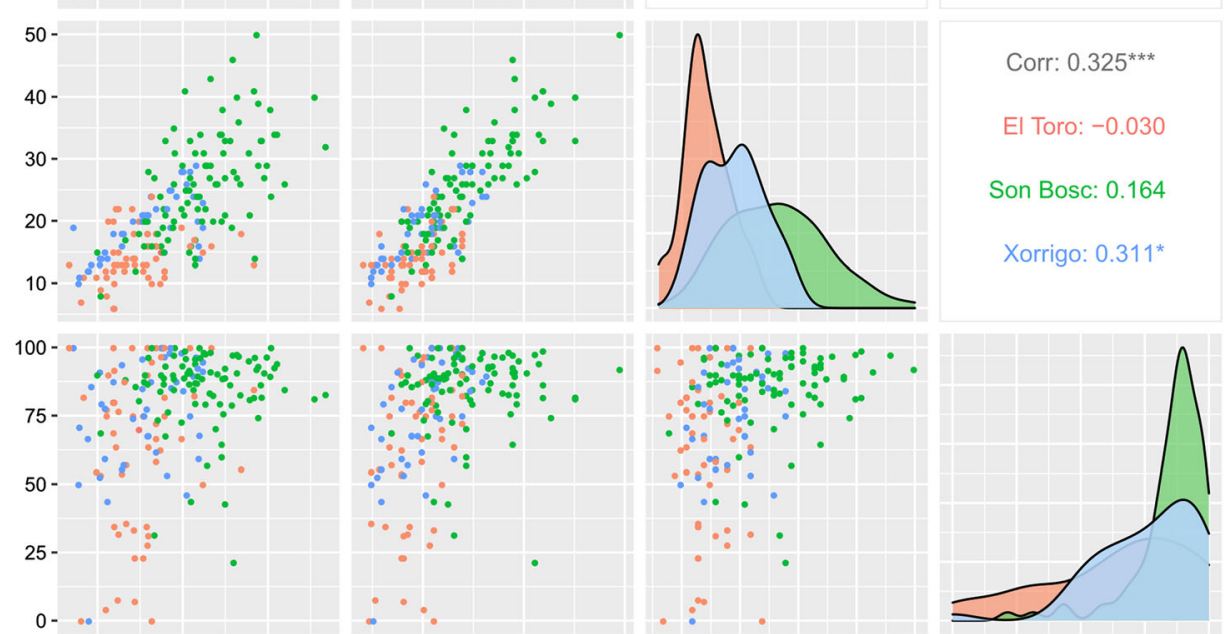

Corr: $0.308^{\star \star \star}$

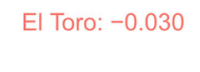

Son Bosc: 0.164

\section{El Toro: 0.152}

Son Bosc: -0.109

Xorrigo: $0.323^{*}$
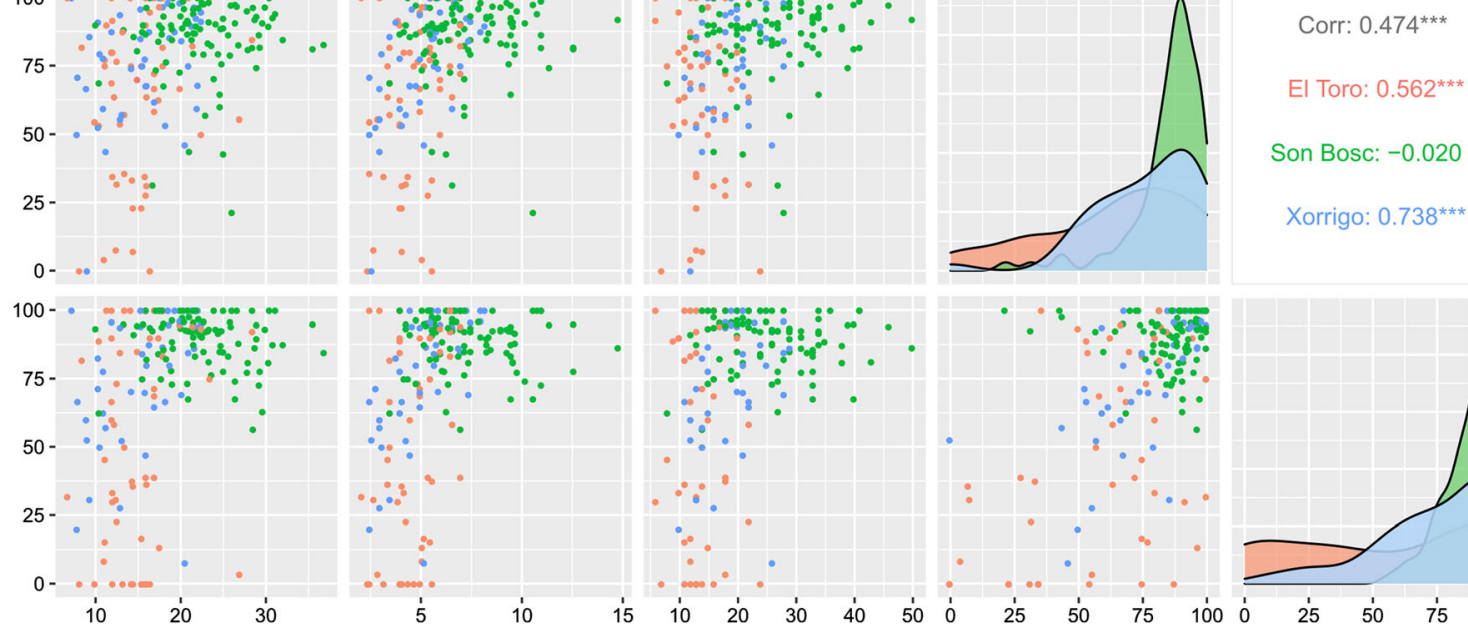

Fig. 3 Correlation matrix for plant features and fitness traits. Numbers above the diagonal indicate the Spearman correlation coefficients. The distribution of each trait is shown on the

This behaviour allows the arrival of large amounts of pollen, in the course of a single pollinator visit, which reduces the risk of pollen limitation and increases the probability of receiving pollen from different individuals.

Outbreeding depression is a good indicator of population isolation and can provide information on diagonal and the correlation plot is shown below the diagonal. Colours indicate localities: Overall (black), El Toro (red), Son Bosc (green) and Xorrigo (blue)

gene flow i.e. in studies of narrowly distributed species (Lara-Ruiz et al. 2008; Cursach and Rita 2012; Sletvold et al. 2012). Outbreeding depression can be higher in rewarding orchids, as pollinators may tend to move less among populations (Jacquemyn and Brys 2010; Suetsugu et al. 2015). However, the interpopulation outcrossing treatment did not indicate a 

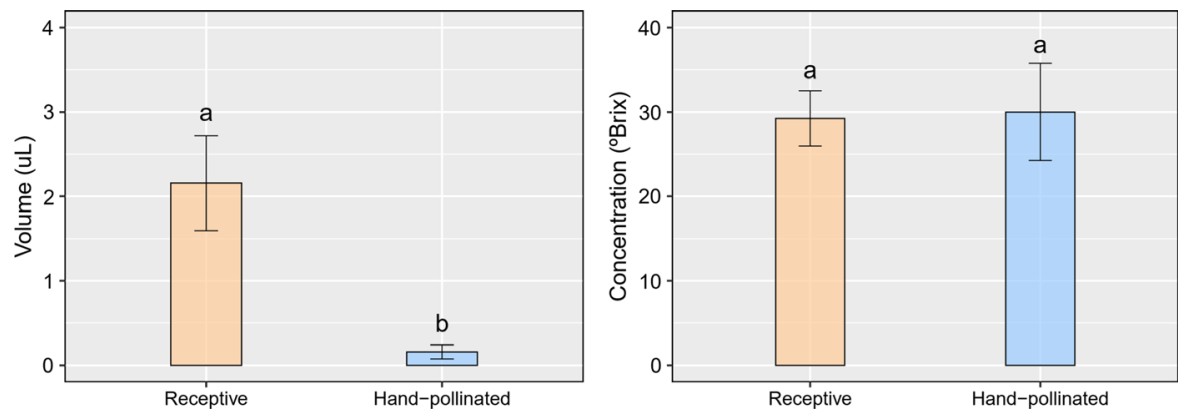

Fig. 4 Mean volume of nectar (left) and concentration of sugar (right) in open-pollinated and hand-pollinated plants. Error bars indicate standard error. Letters indicate Tukey post hoc groups

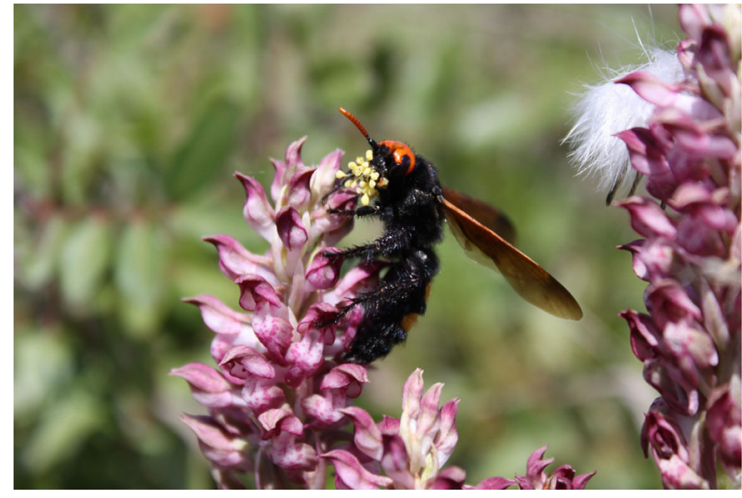

Fig. 5 Image of Anacamptis coriophora flowering stalk being pollinated by Megascolia bidens (Scoliidae) carrying a high number of pollinia likely from both the same and other plants

risk of exogamic depression for A. coriophora, and in this sense, our results show that populations can outcross despite being separated by long distances. At the same time, we did not find any pattern related to heterosis (that is, fixation of deleterious alleles by genetic drift). Therefore, these results indicate a good connection by gene flow which is important for conservation management in areas where the species is rare and law protected (Smithson 2006; Sletvold et al. 2012).

Effects of spatio-temporal changes in plant traits and reproductive success

The populations included in our study exhibited high spatio-temporal variations in biometric plant traits and fitness, probably due to meteorological conditions (in the case of plant traits) and pollinator activity (fitness traits). The population of Son Bosc had the highest plant trait and fitness trait values in all years studied. In particular, this locality has a high richness of both plant and pollinator species (Traveset et al. 2018), which is mainly caused by the optimal abiotic context and meteorological conditions.

The characteristics of Son Bosc site enable target species to benefit from an abundance of pollinators. Due to the high abundance of pollinators and coflowering species (including other orchids such as Anacamptis robusta or Serapias parviflora), it is plausible that a large proportion of pollen may not reach to a conspecific stigma. However, as shown in Fig. 2, the species showed a high fruit set and pollinia removal rate values. In other populations such as El Toro and Xorrigo-where the drier soils are more sensitive to changes in the precipitation between years and there is probably a lower abundance of pollinators-the fruit set and pollinia removal rates significantly exhibited variability between years. Overall, the fruit set and pollinia removal rates were very high, as expected for a rewarding orchid (Jersáková et al. 2006).

Fitness in orchids has been correlated with other phenotypic traits, such as the inflorescence size, as reported for Cephalanthera falcata by Suetsugu et al. (2015) and A. longicornu by Capó et al. (2020b), the spur length as seen in A. morio by Zitari et al. (2011), the number of flowers (Johnson and Nilsson 1999) or the brightness of the corolla (Sletvold et al. 2016). In the case of $A$. coriophora, no correlations were observed between fitness and any plant features, height, inflorescence length or flower number even considering correlations within populations (Fig. 3). These results showed the opposite result than others performed at the same time in populations from France, where plant height was positively correlated with fruit set (Joffard et al. 2020). The lack of a 
correlation between the studied plant traits and fitness features may be caused by the selection of other strategies to attract pollinators such as the production of nectar or synthesis of sweet fragrances. Indeed, individuals of $A$. coriophora subsp. fragrans that emitted high amounts of some volatiles showed the higher fruit set values (Joffard et al. 2020).

Pollination regulates the nectar content

Nectar production is costly and requires a high investment of resources (Dafni and Ivri 1979), which are eventually reallocated to other functions when pollination is accomplished (Luyt and Johnson 2002). In this experiment, the nectar content decreased when pollination was performed, though the sugar concentration was maintained. Thus, the species might relocate sugar and water present in the spur when fecundation is complete. Further studies are necessary to disentangle whether the nectar reabsorbed is relocated to reproductive tissues as observed in other orchid species (Bednara et al. 1981; Nepi and Stpiczyńska 2007) and if this phenomenon can influence to plant fitness.

\section{Conclusions}

The rewarding A. coriophora is close to be self-sterile because only a few seeds produced following selffertilization are viable, unlike deceptive orchids. This species might prevent selfing through two mechanisms: massive post-zygotic failure in the formation of seed embryos and a likely pre-zygotic barrier favouring allopollen. However, this observation could also be related to inbreeding depression. On other hand, the long periods in which flowers are receptive allow the arrival of high amounts of pollen from other individuals and facilitate cross-pollination. In this sense, the large numbers of pollinia transported by pollinators and recurrent flower visits saturate the stigmas with pollen from different origins, which reduces selfing. Thus, this species avoids geitonogamy as it is often the case for non-rewarding orchids but through different mechanisms: by maximizing pollinator visits but setting up pre- and post-zygotic barriers to selfing $v s$ minimizing the number of pollinator visits per inflorescence in non-rewarding species. Further studies must focus on the presence and evolutionary advantages of nectar vs. deception strategies considering that inbreeding depression can be avoided in both cases. Our results indicate that the populations exhibit variation in both plant features (caused by ecological conditions) and plant fitness (due to pollinator activity) between years and localities. Contrary to what has been reported for many orchid species, no significant correlation was observed between any plant feature and fitness even within populations. Considering the role of nectar production, relocation of compounds once the flower is pollinated was observed, but further studies must focus on disentangling its role in the breeding system of this species.

Acknowledgements The authors thank Mr. Antoni Martorell, who is responsible for the private property at Son Bosc, and the Albufera de Mallorca Natural Park for allowing us to work at the study sites. We also thank Mr. Miquel Vallespir for his valuable help with the fieldwork. This research was part of S.P.'s M.Sc. thesis. Andrea Devlin from Science Editing Experts proofread the manuscript.

Author contributions All authors contributed to the study conception and design. Material preparation, data collection and analysis were performed by MC and SP-S. The first draft of the manuscript was written by $\mathrm{MC}$ and JR, and all authors commented on previous versions of the manuscript. All authors read and approved the final manuscript. AD from Science Editing Experts proofread the manuscript.

Funding Open Access funding provided thanks to the CRUECSIC agreement with Springer Nature. This study has not received funds from any source.

Data availability Data and material are available by contacting to the corresponding author.

Code availability Not applicable.

\section{Declarations}

Conflict of interest The authors declare that they do not have any potential conflict of interest.

Ethical approval Not applicable.

Consent to participate Not applicable.

Consent for publication Not applicable.

Open Access This article is licensed under a Creative Commons Attribution 4.0 International License, which permits use, sharing, adaptation, distribution and reproduction in any medium or format, as long as you give appropriate credit to the original author(s) and the source, provide a link to the Creative Commons licence, and indicate if changes were made. The 
images or other third party material in this article are included in the article's Creative Commons licence, unless indicated otherwise in a credit line to the material. If material is not included in the article's Creative Commons licence and your intended use is not permitted by statutory regulation or exceeds the permitted use, you will need to obtain permission directly from the copyright holder. To view a copy of this licence, visit http://creativecommons.org/licenses/by/4.0/.

\section{References}

Aguado Martín LO, Viñuela Sandoval E, Fereres Castiel A (2016) Guía de campo de los polinizadores de España. Ediciones Paraninfo S.A, Madrid

Alomar G, Mayol J, Sastre V (1994) Orquídies de les Balears. Govern Balear. Consellería d'Agricultura i Pesca. Direcció General d'Estructures Agràries i Medi Natural.

Anders Nilsson L (1992) Orchid pollination biology. Trends Ecol Evol 7:255-259. https://doi.org/10.1016/01695347(92)90170-G

Armbruster WS, Rogers DG (2004) Does pollen competition reduce the cost of inbreeding? Am J Bot 91:1939-1943. https://doi.org/10.3732/ajb.91.11.1939

Bednara J, Bednara J, Kuraś M, Rodkiewicz B (1981) Ultrastructural changes during megasporogenesis in Epipactis (Orchidaceae). Acta Soc Bot Pol 50:127-130. https://doi.org/10.5586/asbp.1981.017

Blondel J, Aronson J, Bodiou JY, Boeuf G (2010) The Mediterranean region: biological diversity in space and time. Oxford University Press, Oxford

Borba EL, Semir J, Shepherd GJ (2001) Self-incompatibility, inbreeding depression and crossing potential in five brazilian pleurothallis (Orchidaceae) species. Ann Bot 88:89-99. https://doi.org/10.1006/anbo.2001.1435

Borràs J, Cursach J (2020) Female and male fitness of a sexually deceptive orchid with a narrow distributional area: from phenotypic traits to spatial distribution patterns. Plant Biol. https://doi.org/10.1111/plb.13184

Brys R, Jacquemyn H, Hermy M (2008) Pollination efficiency and reproductive patterns in relation to local plant density, population size, and floral display in the rewarding Listera ovata (Orchidaceae). Bot J Linn Soc 157:713-721. https:// doi.org/10.1111/j.1095-8339.2008.00830.x

Capó M, Borràs J, Perelló-Suau S, Rita J, Cursach J (2020a) Ecological factors affecting the fitness of the threatened orchid Anacamptis robusta (Orchidaceae): habitat disturbance, interactions with a co-flowering rewarding orchid and hybridization events. Plant Biol. https://doi.org/10. 1111/plb.13179

Capó M, Cursach J, Rita J (2020b) Disentangling the pollination system of the food-deceptive orchid Anacamptis longicornu (Orchidaceae): from breeding system to spatiotemporal variation in reproductive success. Plant Biosyst 154:306-315. https://doi.org/10.1080/11263504.2019. 1610110

Charlesworth D, Charlesworth B (1987) Inbreeding depression and its evolutionary consequences. Rev Ecol Syst 18:237-268
Cursach J, Rita J (2012) Reproductive biology and reproductive output assessment in natural and introduced subpopulations of Apium bermejoi, a 'critically endangered' endemic plant from Menorca (western Mediterranean). Nord J Bot 30:754-768. https://doi.org/10.1111/j.1756-1051.2012. 01437.x

Cursach J, Moragues E, Rita J (2013) Herbivory and plant competition effects on the population dynamics of $\mathrm{Nau}$ fraga balearica, a threatened narrow endemic species of the Balearic Islands. Plant Biosyst 147:508-517. https:// doi.org/10.1080/11263504.2012.745456

Dafni A, Ivri Y (1979) Pollination ecology of, and hybridization between, Orchis coriophora L. and O. collina Sol. ex Russ. (Orchidaceae) in Israel. New Phytol 83:181-187. https:// doi.org/10.1111/j.1469-8137.1979.tb00740.x

Darwin C (1887) On the various contrivances by which orchids are fertilized by insects. Unversity of Chicago Press, Chicago

Duffy KJ, Stout JC (2011) Effects of conspecific and heterospecific floral density on the pollination of two related rewarding orchids. Plant Ecol 212:1397-1406. https://doi.org/10.1007/s11258-011-9915-1

Fox J, Weisberg S (2019) An R companion to applied regression, 3rd edn. Sage, Thousand Oaks

Gontijo SL, Barbosa AR, De Melo MC, Borba EL (2010) Occurrence of different sites of self-incompatibility reaction in four Anathallis (Orchidaceae, Pleurothallidinae) species. Plant Species Biol 25:129-135. https://doi.org/10. 1111/j.1442-1984.2010.00277.x

Harder LD, Barrett SCH (1995) Mating cost of large floral displays in hermaphrodite plants. Nature 373:512-515

Internicola AI, Juillet N, Smithson A, Gigord LDB (2006) Experimental investigation of the effect of spatial aggregation on reproductive success in a rewardless orchid. Oecologia 150:435-441. https://doi.org/10.1007/s00442006-0530-0

Jacquemyn H, Brys R (2010) Temporal and spatial variation in flower and fruit production in a food-deceptive orchid: a five-year study. Plant Biol 12:145-153. https://doi.org/10. 1111/j.1438-8677.2009.00217.x

Jacquemyn H, Brys R, Honnay O (2009) Large population sizes mitigate negative effects of variable weather conditions on fruit set in two spring woodland orchids. Biol Lett 5:495-498. https://doi.org/10.1098/rsbl.2009.0262

Jersáková J, Johnson SD (2006) Lack of floral nectar reduces self-pollination in a fly-pollinated orchid. Oecologia 147:60-68. https://doi.org/10.1007/s00442-005-0254-6

Jersáková J, Johnson SD, Kindlmann P (2006) Mechanisms and evolution of deceptive pollination in orchids. Biol Rev 81:219. https://doi.org/10.1017/S1464793105006986

Jersáková J, Johnson SD, Kindlmann P, Pupin AC (2008) Effect of nectar supplementation on male and female components of pollination success in the deceptive orchid Dactylorhiza sambucina. Acta Oecol 33:300-306. https://doi.org/10. 1016/j.actao.2008.01.001

Jersáková J, Johnson SD, Jürgens A (2009) Deceptive behavior in plants. II. Food deception by plants: from generalized systems to specialized floral mimicry. In: Baluska F (ed) Plant-environment interactions: signalling and communication in plants. Springer, Berlin, pp 223-246 
Joffard N, Le Roncé I, Langlois A, Renoult J, Buatois B, Dormont L, Schatz B (2020) Floral trait differentiation in Anacamptis coriophora: phenotypic selection on scents, but not on colour. J Evol Biol 33:1028-1038. https://doi. org/10.1111/jeb.13657

Johnson SD, Nilsson LA (1999) Pollen carryover, geitonogamy, and the evolution of deceptive pollination systems in orchids. Ecology 80:2607-2619. https://doi.org/10.1890/ 0012-9658(1999)080[2607:PCGATE]2.0.CO;2

Johnson SD, Peter CI, Nilsson LA, Ågren J (2003) Pollination success in a deceptive orchid is enhanced by co-occurring rewarding magnet plants. Ecology 84:2919-2927. https:// doi.org/10.1890/02-0471

Johnson SD, Peter CI, Ågren J (2004) The effects of nectar addition on pollen removal and geitonogamy in the nonrewarding orchid Anacamptis morio. Proc R Soc B Biol Sci 271:803-809. https://doi.org/10.1098/rspb.2003.2659

Kropf M, Renner SS (2008) Pollinator-mediated selfing in two deceptive orchids and a review of pollinium tracking studies addressing geitonogamy. Oecologia 155:497-508. https://doi.org/10.1007/s00442-007-0919-4

Lara-Ruiz P, Chiarello AG, Santos FR (2008) Extreme population divergence and conservation implications for the rare endangered Atlantic Forest sloth, Bradypus torquatus (Pilosa: Bradypodidae). Biol Conserv 141:1332-1342. https://doi.org/10.1016/j.biocon.2008.03.002

Larson BM, Barrett SC (2000) A comparative analysis of pollen limitation in flowering plants. Biol J Linn Soc 69:503-520. https://doi.org/10.1111/j.1095-8312.2000.tb01221.x

Luyt R, Johnson SD (2002) Postpollination nectar reabsorption and its implications for fruit quality in an epiphytic orchid. Biotropica 34:442-446. https://doi.org/10.1111/j.17447429.2002.tb00558.x

Martos F, Cariou ML, Pailler T, Fournel J, Bytebier B, Johnson SD (2015) Chemical and morphological filters in a specialized floral mimicry system. New Phytol 207:225-234. https://doi.org/10.1111/nph.13350

Mitchell RJ, Karron JD, Holmquist KG, Bell JM (2004) The influence of Mimulus ringens floral display size on pollinator visitation patterns. Funct Ecol 18:116-124. https:// doi.org/10.1111/j.1365-2435.2004.00812.x

Neiland MRM, Wilcock CC (1995) Maximisation of reproductive success by European orchidaceae under conditions of infrequent pollination. Protoplasma 187:39-48. https:// doi.org/10.1007/BF01280231

Neiland MRM, Wilcock CC (1998) Fruit set, nectar reward, and rarity in the Orchidaceae. Am J Bot 85:1657-1671. https:// doi.org/10.2307/2446499

Nepi M, Stpiczyńska M (2007) Nectar resorption and translocation in Cucurbita pepo L. and Platanthera chlorantha Custer (Rchb.). Plant Biol 9:93-100. https://doi.org/10. 1055/S-2006-924287

Parra-Tabla V, Vargas CF, Magaña-Rueda S, Navarro J (2000) Female and male pollination success of Oncidium ascendens Lindey (Orchidaceae) in two contrasting habitat patches: forest vs agricultural field. Biol Conserv 94:335-340. https://doi.org/10.1016/S0006-3207(99)00187-1

Peter CI, Johnson SD (2009) Autonomous self-pollination and pseudo-fruit set in South African species of Eulophia (Orchidaceae). S Afr J Bot 75:791-797. https://doi.org/10. 1016/j.sajb.2009.07.007
Price MV, Waser NM, Irwin RE, Campbell DR, Brody AK (2005) Temporal and spatial variation in pollination of a montane herb: a seven-year study. Ecology 86:2106-2116. https://doi.org/10.1890/04-1274

R Core Team (2019) R: a language and environment for statistical computing

Ramis C, Romero R, Homar V, Alonso S, Jansà A, Amengual A (2017) On the drought in the Balearic Islands during the hydrological year 2015-2016. Hazards Earth Syst Sci 17:2351-2364. https://doi.org/10.5194/nhess-17-23512017

Rankou H (2011) Anacamptis coriophora. In: IUCN Red List of Threatened Species

Renner SS (2006) Rewardless flowers in the angiosperms and the role of insect cognition in their evolution. In: Waser NM, Ollerton J (eds) Plant-pollinator interactions: from specialization to generalization. University of Chicago Press, Chicago, pp 123-144

Schiestl FP (2005) On the success of a swindle: pollination by deception in orchids. Naturwissenschaften 92:255-264. https://doi.org/10.1007/s00114-005-0636-y

Schiestl FP, Ayasse M, Paulus HF, Löfstedt C, Hansson BS, Ibarra F, Francke W (2000) Sex pheromone mimicry in the early spider orchid (Ophrys sphegodes): patters of hydrocarbons as the key mechanism for pollination by sexual deception. J Comp Physiol A Sens Neural Behav Physiol 186:567-574. https://doi.org/10.1007/s003590000112

Scopece G, Schiestl FP, Cozzolino S (2015) Pollen transfer efficiency and its effect on inflorescence size in deceptive pollination strategies. Plant Biol 17:545-550. https://doi. org/10.1111/plb.12224

Scopece G, Juillet N, Lexer C, Cozzolino S (2017) Fluctuating selection across years and phenotypic variation in fooddeceptive orchids. PeerJ. https://doi.org/10.7717/peerj. 3704

Seavey SR, Bawa KS (1986) Late-acting self-incompatibility in angiosperms. Bot Rev 52:195-219. https://doi.org/10. 1007/BF02861001

Sletvold N, Grindeland JM, Zu P, Ågren J (2012) Strong inbreeding depression and local outbreeding depression in the rewarding orchid Gymnadenia conopsea. Conserv Genet 13:1305-1315. https://doi.org/10.1007/s10592-0120373-7

Sletvold N, Trunschke J, Smit M, Verbeek J, Ågren J (2016) Strong pollinator-mediated selection for increased flower brightness and contrast in a deceptive orchid. Evolution (n Y) 70:716-724. https://doi.org/10.1111/evo.12881

Smithson A (2002) The consequences of rewardlessness in orchids: reward-supplementation experiments with Anacamptis morio (Orchidaceae). Am J Bot 89:1579-1587. https://doi.org/10.3732/ajb.89.10.1579

Smithson A (2006) Pollinator limitation and inbreeding depression in orchid species with and without nectar rewards. New Phytol 169:419-430. https://doi.org/10. 1111/j.1469-8137.2005.01592.x

Smithson A, Gigord LD (2001) Are there fitness advantages in being a rewardless orchid? Reward supplementation experiments with Barlia robertiana. Proc Biol Sci 268:1435-1441. https://doi.org/10.1098/rspb.2001.1705

Suetsugu K, Naito RS, Fukushima S, Kawakita A, Kato M (2015) Pollination system and the effect of inflorescence 
size on fruit set in the deceptive orchid Cephalanthera falcata. J Plant Res 128:585-594. https://doi.org/10.1007/ s10265-015-0716-9

Traveset A, Castro-Urgal R, Rotllàn-Puig X, Lázaro A (2018) Effects of habitat loss on the plant-flower visitor network structure of a dune community. Oikos 127:45-55. https:// doi.org/10.1111/oik.04154

Tremblay RL (1992) Trends in the pollination ecology of the Orchidaceae: evolution and systematics. Can $\mathrm{J}$ Bot 70:642-650. https://doi.org/10.1139/b92-083

Tremblay RL, Ackerman JD (2007) Floral color patterns in a tropical orchid: are they associated with reproductive success? Plant Species Biol 22:95-105. https://doi.org/10. 1111/j.1442-1984.2007.00181.x

Tremblay RL, Ackerman JD, Zimmerman JK, Calvo RN (2005) Variation in sexual reproduction in orchids and its evolutionary consequences: a spasmodic journey to diversification. Biol J Linn Soc 84:1-54. https://doi.org/10.1111/j. 1095-8312.2004.00400.x

Tremblay RL, Ackerman JD, Pérez ME (2010) Riding across the selection landscape: fitness consequences of annual variation in reproductive characteristics. Philos Trans $\mathrm{R}$ Soc B Biol Sci 365:491-498. https://doi.org/10.1098/rstb. 2009.0239

Vázquez Pardo FM (2009) Revision of the Orchidaceae family in Extremadura (Spain). Folia Bot Extrem 3:7-365

Wong DCJ, Pichersky E, Peakall R (2017) The biosynthesis of unusual floral volatiles and blends involved in orchid pollination by deception: current progress and future prospects. Front Plant Sci 8:1955. https://doi.org/10.3389/fpls. 2017.01955

Zitari A, Tranchida-Lombardo V, Cafasso D, Helal AN, Scopece G, Cozzolino S (2011) The disjointed distribution of Anacamptis longicornu in the West-Mediterranean: the role of vicariance versus long-distance seed dispersal. Taxon 60:1041-1049. https://doi.org/10.1002/tax.604008

Publisher's Note Springer Nature remains neutral with regard to jurisdictional claims in published maps and institutional affiliations. 